\title{
Garden of Disorder: Rethinking the Effectiveness of Aesthetic Experiences
}

\author{
Qing Yong \\ Art College \\ Sichuan University \\ Chengdu, China \\ School of Media and Arts \\ Chongqing University of Posts and Telecommunications \\ Chongqing, China
}

\begin{abstract}
Aesthetics is an autonomous garden, which has become a trustworthy force in opening a new world for mankind due to its non-utilitarian nature. However, aesthetic autonomy is not the same as artistic autonomy. By distinguishing the similarities and differences between aesthetic games and aesthetics, as well as aesthetic autonomy and artistic autonomy, this paper concludes that people still need to return to Schiller's "game" to find the essence of aesthetic experience. In what Jacques Rancière calls "sense of difference," the aesthetic experience is still valid.
\end{abstract} game

Keywords-aesthetic experience; artistic autonomy; aesthetic

\section{INTRODUCTION}

Similarly, Peony Pavilion and Romance of the Western Chamber, both classical Chinese dramas, place the events of the protagonist's search for self and the breakthrough of the code of conduct in the garden. In Peony Pavilion, Du Liniang sneaked into the back garden under the guidance of her maid Chun Xiang, and returned to dream of meeting a scholar in the garden and enjoying the pleasure between the sheets action; in Romance of the Western Chamber, Zhang Sheng and Cui Yingying also recited poems, showed their love for each other, and listened to the piano to tryst in the back garden. The garden is one of the few places these women can visit, and the privacy and semi-publicity of ancient private gardens make it possible for the men and women to meet. Such explanation seems to find the rationality of the garden in the drama. Consciousness, however, precedes action. What makes people in the drama, such as Du Liniang and Cui Yingying, involuntarily emerge and look back on themselves, brewing the desire and courage to break through the restrictions, and then take action? It is clear that the garden is not only a physical place for these young people to transgress the norms of social behavior, but also a field to germinate their self-consciousness and urge them to rebel and liberate. Such theatrical garden experience is too mysterious for the author. But at the 56th La Biennale di Venezia, the author seemed to capture that mystery, or rather to be caught up in it, when the author saw The Last Garden by the American artist Sarah Sze.

\section{GARDEN EXPERIENCE}

Walking into Sarah Sze's garden was like bumping into a stranger's world when the owner wasn't at home. Blue wool was woven into the shape of a hammock in the doused shade, but apparently it could not bear a man's weight. Above the hammock, a pale rock suspended by thin ropes, suspended in a confrontation of steady but undependable forces, produced a strange stillness, as if the author were watching a slice of time. In the middle of the garden there was a moss-covered round stone wall, from which hung a thin string, tied at one end to a small rock. What was tied at the other? Curiosity led the author around the wall, and to her surprise, the other end of the rope was also tied to a rock. That means if the author sees the stone first, she'll still walk around the wall. Torn photographs, pictures, pieces of paper were inserted in the cracks in the wall, and a circular mirror was placed high up ... All the devices seem to have been accidentally picked up by the owner of the yard, but at the same time they occupy their place in the whole situation and fulfill their destiny. In this small, overgrown yard tucked away in the corner, curiosity and sensibility are activated at the same time, the breeze of the hanging line, the toughness of the line activated by the weight of the stone, the hidden secret... It was as if a mysterious force had summoned them. They spring from themselves - not from the author's imagination, but from the author's body - they are confirmed by the experience of the author's body, calling the author to be their witness. And when these common things become so significant, the author, the observer who has contributed the author's body, follow the signals they send the author, and find the self of the author, in all things, in myself (by Mikel Dufrenne), and all new possibilities are possible after the self is established.

The so-called mystical experience the author acquired in the art work the last garden is not actually mysterious. There is already a corresponding term: "aesthetic experience". This paper will not discuss whether Du Liniang's experience in the garden is aesthetic experience, and whether there is a difference between natural aesthetic experience and art aesthetic experience. If Du Liniang got a similar aesthetic experience in the garden, which provided the possibility for 
the object of beauty. However, this is quite different from the original meaning of the word "game" in "aesthetic game". The word "game" usually refers to the state that is accidental in both subjective and objective aspects, that is, it is not subject to external and internal oppression at the same time. In other words, if aesthetics is only the initiative of the subject, how can there be a game? Schiller's vision of aesthetic game is revelatory. In Schiller's opinion, people have three kinds of impulses: emotional impulse, formal impulse and game impulse. In the emotional impulse, man is subject to the compulsion of natural demand; in the formal impulse, that is, the rational impulse, man is subject to the compulsion of rational demand; only in the game impulse, man eliminates the compulsion from inside and outside, and achieves freedom in spirit and material aspects, and the object of the game impulse is beauty. Aesthetics is the game itself. Beauty is not only an object. It is the material itself, but also a condition of the subject. In short, there is a real unity and conversion between material and form, as well as between passivity and activeness, rather than a relationship of opposites or dominance of one party over the other.

When the word "game" in the "aesthetic game" is eliminated, the aesthetic gradually becomes the product of human spirit. The free and equal relationship between man and the world that the "aesthetic game" promises without initiative and passivity, apart from purpose and intention, is transformed into the "aesthetic" activity of how human beings perceive beauty. Through aesthetic interpretation of aesthetic experience, human beings transform the world into their own perception mechanism, and the world no longer has secrets and mysteries, because this perception mechanism is only related to human activities, only the mirror image of human activities, and the original relationship between human beings and the world that they hope to get access to through beauty thus goes astray. The term "aesthetic object" presents this variation most directly, that is, all "free representations" become objects of the subject, which stand in front of people and are viewed by the subject with a set of perceptual mechanisms defined by aesthetics. According to Heidegeer, this perceptual mechanism makes the existent stand in front of people as a system, and the world is no longer universal, but pictorial. Heidegger's insights are so sharp and profound that they reveal the finitude and self-seclusion of this seemingly scientific and perfect aesthetic world. thinker, also believes that aesthetic games have lost their original purpose, and aesthetics have been transformed into products of the human spirit. Therefore, people can briefly review how aesthetics defines aesthetic experience. Aesthetics defines beauty and aesthetic perception as a set of perfect knowledge, legislates for it, and quietly separates beauty and aesthetics from human world and human activities, transforming human aesthetic game into perceptual epistemology and perceptual logic. The origin of aesthetics is Descartes' subjectivism. All existence and the certainty of all truth are based on individual selfconsciousness. The thinking self is the standard of everything. The ego of the subject essentially dictates how everything that happens to the author is to be what it is. Under this philosophy, the contemplation of beauty is completely focused on the subject's state of feeling related to

\section{B. Sensible Heterogeneity - from the Autonomy of Aesthetic Experience to the Autonomy of Art}

The active and passive suspension in the aesthetic game, that is, the absence of the distinction between subject and object, truly guarantees the "unavailability" of the object in the aesthetic experience, which exists outside the control of the subject as a free representation, and the aesthetic experience defined by aesthetics is the feeling of the subject to the object. Thus, art, as the truth of sensibility and perception, is transformed into art as a copy of the perceptual world or a static subject's perceptual expression. When art is no longer used to open real events, but to express the subject's sensibility, aesthetics and art "dissolve into pure 
feelings and gradually sink into the totter of nothingness". Heidegger launched a fierce criticism on this, and he chose Wagner as the object of criticism. Wagner believed that the weakening of artistic sensibility led to the decline of art, so he tried to save art by strengthening the "feeling effect". Wagner proposed that "comprehensive works of art" use various artistic means to highlight the music effect of sensation, "make all solid things melt into a flowing soft, flexible state, melt into light and stumbling; A pure and infinite night without law or limit, without clarity or rule thus formed". Heidegger believed that this kind of crazy way to strengthen sensibility had reached the point of being immersed in the pure excitement and boiling of the feelings in oneself, and the excessive overflows resulted in Schopenhauer's "nothingness", which created the "aesthetic man" far away from the reality of existence.

The importance of sensory acquisition, of course, does not begin with Wagner, but with Plato. Plato's inquiry into art and beauty gave rise to the basic proposition of dividing the boundaries of artistic exploration, in which the concepts of form and matter laid the foundation for sensibility to obtain its status. Works of art manifest themselves as forms and are experienced by people. Form conquers matter, laying a self-evident foundation for man to transform the world into his own perceptual mechanism. The proposition of the spirit of form in modern art is "perceptive heterogeneity". From Greenburg to Adorno to Lyotard, human attempts to achieve self-redemption through aesthetic experience have all staked on this perceptive heterogeneous power. However, this is not so much the road of human self-salvation as the channel for art to obtain its legitimacy and validity. Furthermore, this is another way for the human spirit to manifest itself. The free and equal state of aesthetic games is replaced by a perceptual mechanism initiated by art. As described earlier, the perception mechanism is only a mirror image of human activities, although it seems to be settled in the "form" and "content" completely independent of the human spirit, but in essence, all of these pure content needs the light of the human spirit, because the human spirit in a more clever way (compare the rationality, thought more clever and effective) to gain legitimacy, as human spirit has legitimized itself in more ingenious ways (more rational, more ingenious and more effective in thought), and it has given art the right to witness the invisible, through which the subject can still feel that he is still capable of overcoming finitude and of being free. By granting this right, the human spirit has once again manifested itself.

Sensible heterogeneity makes art a monument to the power of the unthinkable, chaotic and extreme otherness, which can be revealed anywhere illuminated by the human mind. Therefore, no matter the daily articles, commodities, ancient relics, or classical art, avant-garde art, can be included in the territory of art, to achieve the reaesthetization. The all-encompassing debate over the territory of art, and that is, whether art is folly or transcendence or confrontation, may therefore be missing the point, whether art is still valid and whether aesthetic experience is still valid. First of all, it is necessary to answer what kind of sensory heterogeneity and what kind of aesthetic experience this is.

\section{WAY TO RETURN TO THE GARDEN}

After the aesthetic lost the essence of Schiller's "game", art conflicts and lingers between the emotional impulse and the rational impulse. With the fierce criticism of the enlightenment rationality by the aesthetic modernity, the pendulum of art turns to the perceptual impulse, and the infatuation of the finiteness of the pure object, the body and the sex makes the art present a falling tendency from the sublime spirit to the finiteness. This falling process belies its essence by belittling reason and promoting sensibility. That is, another presence of the human spirit as the subject, and when the thought of the body - perception, sensibility, falling down for the body itself — has an absolute finitude, art and "aesthetic experience" have nothing to do with the opening of a new destiny for mankind. When people step into the garden of art and "aesthetic experience", they can only see ourselves.

Therefore, it may not be that the aesthetic experience is no longer effective, but that the aesthetic experience is no longer the other aesthetic experience. Aesthetic experience and art are still the trustworthy power to open up the new light of the world. The advice given by the French thinker Jacques Rancière on how to return to the garden is clearly worth attention. To return to this garden, people need to be more thorough and return to the "aesthetic game" in which form and matter are not opposed, and both active and passive are suspended. Among them, people are not the subject of perception, and art is not a tool for people to express their feelings. The important thing is not to search endlessly for the heterogeneity of sense, but to create a "sense of difference". There is a profound difference between the heterogeneity of sense of difference and perception. The latter is like a distant promise to circle an emotional kingdom outside the world, and the whole point of art is to deconstruct and escape meaning. For this reason, the heterogeneity that Liotta valued only existed in objects lacking timbre, tone and color. Liotta interpreted art as a place of negative expression with the theory of "sensory heterogeneity", that is, art only witnessed the finitude itself. However, sense of difference is a conflict between perceptual presentation and its sense of meaning, which interrupts the consensus between perceptual presentation mode and meaning mechanism through "aesthetic game", so as to change the landscape of possibility. Art becomes such a place that, as Rancière says, "it creates an environment of sensibility," And so people can wander through it, as the author did when she walked into Sarah Sze's The Last Garden, the mysterious experience that caught me, that took the author away from everyday experience, that no given decoding program could guide her or constrain how she saw or felt. It is in this conflict of perceptions that everything in this garden is free at the same time as the author is. Things that the author had never noticed, with their slight shifts and sounds, suddenly became startling and meaningful, and they were confirmed by the author's body's perception, which at the same time gave birth to a new body of mine. The author suddenly saw and felt something unprecedented, which may be the inducement for Du Liniang and Cui Yingying to unfold their new destiny in the garden. 


\section{CONCLUSION}

According to Plato, politics is born when a man destined to remain in the invisible inner sphere of work and reproduction, doomed to do "nothing else," suddenly takes the time he "never had" to assert with certainty that they belong to a common world. This is the effect of what Rancière calls "sense of difference," in which the world and people are about to embark on a new destiny, and perhaps they can say that the aesthetic experience is still valid.

\section{REFERENCES}

[1] Mikel Dufrenne. Aesthetics and philosophy. China Social Sciences Press. 1985. 3. (in Chinese)

[2] Yu Hong. the Thinking-to-Poeticizing Dialogue': An Introduction to Heidegeer's Poetics. China Social Sciences Press, 1991, 83. (in Chinese)

[3] Schiller, On Beauty, quoted from History of the Western Aesthetics by Zhu Guangqian. People's Literature Publishing House, 2011, 430. (in Chinese)

[4] Heidegger. Nietzsche, Volume 1( English version), 83.

[5] Yu Hong. the Thinking-to-Poeticizing Dialogue': An Introduction to Heidegeer's Poetics. China Social Sciences Press, 1991, 79. (in Chinese)

[6] Jacques Rancière. Speaking, Showing, and Doing: Between Politics and Art. Art Time. 2013. 7. (in Chinese) 